R G J FRANK J D BOS

Department of Dermatology, Academisch Medisch Centrum Amsterdam, Holland F W vd MEULEN Laser Centre,

Academisch Medisch Centrum Amsterdam, Holland

Address correspondence to: Dr Frank.

1 Kennedy JC, Pottier RH, Pross DC. Photodynamic therapy with endogeneous protoporphyrin IX: basic principle and present clinical experience. $\mathcal{f}$ Photochem Photobiol B 1990;6:143-8.

Accepted for publication 19 September 1995

Systemically administered interferon alfa-2a prevents recurrence of condylomata acuminata following $\mathrm{CO}_{2}$-laser ablation. The influence of the cyclic lowdose therapy regimen. Results of a multicentre double-blind placebocontrolled clinical trial

From placebo-controlled clinical trials it has been concluded that subcutaneous interferon (IFN) alfa-2a is not effective as a monotherapy in the treatment of refractory condylomata acuminata at a dose of 1.5 megaunits if given continuously three times a week for four weeks. ${ }^{1}$ Contrasting results, however, have been obtained with IFN gamma given as a monotherapy "cyclically" up to 2 megaunits daily for 7 days, followed by a 4 week pause ( 1 cycle) for up to 4 cycles. $^{2}$ This has led to the hypothesis that either the type of IFN or the treatment regimen were responsible for the differences. In addition, another controlled study administering IFN alfa-2a (3 megaunits/tiw, s.c.) given continuously adjuvantly to $\mathrm{CO}_{2}$-laser did not show any superiority to placebo, ${ }^{3}$ whereas a cyclic application of IFN alpha in an open study showed lower recurrence rates in the IFN group. ${ }^{4}$ Therefore, we argued that the therapy regimen used could be the main reason for the observed treatment failure.

In contrast, in our study IFN alfa-2a was given cyclically adjuvent to $\mathrm{CO}_{2}$-laser, comprising 5 days treatment with 1 megaunit/day and a 4 week treatment-free interval ( 1 cycle) up to a maximum of 3 cycles, leading to a total of 15 megaunits of IFN alfa-2a. The follow-up lasted 18 weeks. The evaluation of efficacy was done by the comparison of recurrence rates at week 33. A total of 84 patients (equally distributed to the therapeutic arms) were included in the study, out of which 32 (IFN alfa-2a) and 35 (placebo) respectively were evaluated at week 33. At the endpoint of the

Cumulative frequency of recurrences of condylomata acuminata after treatment with interferon alfa-2a (Roferon $\left(\mathrm{A}-\mathrm{A}\right.$ ) and $\mathrm{CO}_{2-}$ laser in relation to time to recurrence.

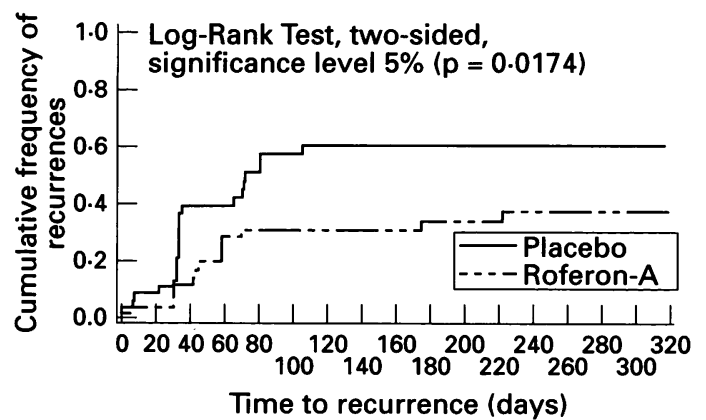

study 13 out of $32(41 \%, 95 \%$ confidence interval, $24-59 \%$ ) of the IFN group and 22 out of 35 patients $(63 \%, 95 \%$ confidence interval $45-79 \%$ ) of the placebo group showed a recurrence of the condylomata. This difference is significant at a level of significance of $5 \%\left(\chi^{2}=3,312\right.$, critical value for one-sided testing at $5 \%$ level: 2,076 ). Figure 1 shows the cumulative frequency of recurrence of the condylomata in relation to time after surgery. The log rank two-sided test revealed statistically significant differences at a $5 \%$ level $(p=$ $0.0174)$. The treatment was generally well tolerated. Eight patients from each group (19\%) complained of side effects, usually mild to moderate. No drop outs due to side effects were observed.

Summarising our data, it seems that cyclic application of low dose IFN alfa-2a adjuvant to $\mathrm{CO}_{2}$-laser ablation is superior in the treatment of condylomata acuminata compared to adjuvant continuous application of interferon or placebo, both in terms of recurrence rate and time to recurrence.

$$
\begin{array}{r}
\text { G GROSS } \\
\text { A ROUSSAKI } \\
\text { Hamburg-Eppendorf, } \\
\text { Martinistr. 52, } \\
\text { S BAUR } \\
20246 \text { Hamburg (Germany) } \\
\text { S Mrauenklinik der Universität München, } \\
\text { Maistr. 11, } \\
80337 \text { München (Germany) } \\
\text { M WIEGAND } \\
\text { A MESCHEDER } \\
\text { Hoffmann-La Roche AG, } \\
\text { Oncology/Immunology, } \\
\text { Emil-Barellstr. 1 } \\
\text { 79630 Grenzach-Wyhlen (Germany) } \\
\text { and the Condylomata Acuminata Study Group }
\end{array}
$$

Correspondence to: Dr Gross.

This study was supported by Hoffmann-La Roche AG, Grenzach-Wyhlen, Germany.

1 The Condylomata International Collaborative Study Group. Recurrent Condylomata acuminata treated with recombinant interferon-alpha 2a: a multicenter doublerecombinant interferon-alpha 2a: a multicenter doubleblind placebo-controlled

2 Gross G, Degen KW, Fierlbeck G et al. Recombinant interferon gamma in anogenital warts: results of a multicente placebo-controlled clinical trial. $\mathcal{f}$ Interferon Res 1991 119:76.

3 The Condylomata International Collaborative Study Group. Randomized placebo-controlled double-blind combined therapy with laser surgery and systemic interferon-alpha-2a in the treatment of anogenital condylomata acuminata. $\mathcal{F}$ Infect Dis 1993;167:824-9.

4 Hohenleutner U, Landthaler M, Braun-Falco O. Postoperative adjuvant therapy with interferon alfa-2b followoperative adjuvant therapy with interferon alfa-2b following laser surgery

Accepted for publication 2 November 1995.

Herpes simplex virus infection in women: viral subtypes and epidemiological features in a district hospital

The incidence of genital herpes is reportedly on the increase in many parts of the UK, ${ }^{1-4}$ and herpes simplex virus type 1 (HSV 1) has become the predominant subtype in genital infections in women. ${ }^{2-5}$ Reasons for the apparent increase in genital herpes in general, and HSV 1 in particular, are as yet unclear.

The aim of this study was to describe the proportions of HSV types 1 and 2 in women presenting with a first symptomatic episode of genital herpes at our genitourinary medicine (GUM) clinic; and compare clinico-epidemiological features of the two subtypes of HSV.

All women $(n=121)$ with a first sympto- 
matic episode of genital herpes infection presenting to the GUM clinic at North Staffordshire hospital between January 1994 and May 1995 were included in the study. HSV was isolated on either MRC-5 or Vero cell monolayers (BioWhittaker, UK); and typed by Direct Immunofluorescence assay, using FITC conjugated monoclonal antibody against HSV 1 and 2 (PHLS, London). Demographic, microbiological and clinical information obtained from patients' clinical notes was analysed using Epiinfo statistical software. The chi square test was used to determine statistical significance.

The table summarises the main clinical and epidemiological findings. Women with HSV types 1 and 2 were comparable in all other features except mean age and mode of referral (table). Patients with either type of HSV had a low prevalence $(4 \%)$ of concurrent STD (compared with other STD patients in our clinic $^{67}$ ): Chlamydia-1, Trichomoniasis-1, genital warts-3. Sixteen patients (14\%) had a past history of STD, 7 and 9 of them had HSV 1 and 2, respectively. Of 118 women for whom information was available, 17 (8 with HSV 1 and 9 with HSV 2) gave a personal history of labial herpes. Similarly, only 27 out of 101 respondents had partners who suffered from "cold sores". There was no association between reported history of herpes labialis in sexual partner and HSV type, $\mathrm{p}=0.06$.

The proportion of HSV types 1 and 2 has remained relatively stable in our catchment population over the last 10 years. In 1985/86, HSV 1 and 2 each accounted for $50 \%$ of genital herpes infections in women in our clinic (Stocker DI, unpublished data). Thus the proportion of HSV 1 in women in our clinic was initially higher than some other clinics in the $\mathrm{UK},{ }^{15}$ but has apparently remained stable and has since been overtaken by other clinics. ${ }^{2-4}$

HSV 1 and 2 seem to have similar clinical and epidemiological features, at least in women. For both viral subtypes most patients

Epidemiological and clinical features

\begin{tabular}{|c|c|c|c|c|}
\hline Feature & HSV 1 & HSV 2 & p value & Total \\
\hline & $62(51)$ & $59(40)$ & & 121 \\
\hline \multicolumn{5}{|l|}{ Age distribution mean } \\
\hline $16-19$ & $14(22 \cdot 6)$ & $7(12 \cdot 3)$ & NS & $\begin{array}{l}20 \cdot 3(0) \\
21(18)\end{array}$ \\
\hline $20-25$ & $28(45 \cdot 2)$ & $23(40 \cdot 4)$ & NS & $51(42)$ \\
\hline $26-40$ & $17(27 \cdot 4)$ & $19(33.3)$ & NS & $36(30)$ \\
\hline$>40$ & $3(4 \cdot 8)$ & $8(14.0)$ & NS & $11(9)$ \\
\hline \multicolumn{5}{|l|}{ Last coitus (days) } \\
\hline $1-7$ & $42(70)$ & $29(54)$ & NS & $71(62)$ \\
\hline $8-14$ & $16(27)$ & $15(28)$ & NS & $31(27)$ \\
\hline$>14$ & $2(3)$ & $10(18)$ & NS & $12(11)$ \\
\hline \multicolumn{5}{|c|}{ Onset of symptoms (days) } \\
\hline $1-3$ & $17(35)$ & $9(21)$ & NS & $26(26)$ \\
\hline $4-7$ & $26(54)$ & $26(62)$ & NS & $52(52)$ \\
\hline$>7$ & $5(11)$ & $7(17)$ & NS & $12(12)$ \\
\hline \multicolumn{5}{|c|}{ Sexual partners past 3 months } \\
\hline mean $(\mathrm{SD})$ & $1 \cdot 1(0 \cdot 3)$ & $1.3(0.9)$ & NS & $1 \cdot 2(0.7)$ \\
\hline Regular only & $58(95)$ & $46(81)$ & NS & $104(88)$ \\
\hline Casual only & $1(2)$ & $1(2)$ & NS & $2(2)$ \\
\hline Regular \& casual & $2(3)$ & $10(17)$ & NS & $12(10)$ \\
\hline \multicolumn{5}{|l|}{ Mode of attendance } \\
\hline Self-referral & $17(28)$ & $24(41)$ & NS & $41(34)$ \\
\hline GP referral & $41(67)$ & $27(47)$ & 0.02 & $68(57)$ \\
\hline Other & $3(5)$ & $7(12)$ & NS & $10(9)$ \\
\hline \multicolumn{5}{|l|}{ Occupation } \\
\hline Employed & $33(55)$ & $44(76)$ & NS & $77(65)$ \\
\hline Student & $13(22)$ & $5(9)$ & NS & $18(15)$ \\
\hline Unemployed & $14(23)$ & $9(15)$ & NS & $23(20)$ \\
\hline
\end{tabular}

SD = Standard deviation; NS = statistically significant.

${ }^{\star}$ Unless specified otherwise, figures in parentheses denote percentages. were in stable sexual relationships (table) and the prevalence of concomitant STD was very low $(4 \%)$. However, women with HSV 1 were younger $(p<0.002)$; and more likely to be referred by their general practitioner $(p<$ 0.02 ) than women with HSV 2. Scoular et al also found a high proportion of women aged 25 years or under among women with HSV 1 infection. Possible explanations for younger patients with HSV 1 include: low herd immunity in socially privileged societies, changes in sexual practices which favour oral-genital transmission and autoinfection. Nageswaran $e t$ $a l^{8}$ noted that women with HSV 1 were more likely to consult their general practitioner prior to GUM clinic attendance. In that study, selfreferred patients (mostly with HSV 2) were more likely to have had an STD before. Past history of STD was comparable in our patients with HSV $1(12 \%)$ or HSV 2 (15\%). However, women aged 25 years or under were more likely to consult their general practitioner first; accounting for $72 \%$ of 67 general practitioner referrals compared with $49 \%$ of 39 self-referrals, $p<0.01$. Hence younger age could explain the larger proportion of general practitioner referrals among women with $\mathrm{HSV}$ 1 than HSV 2 infection in our study.

That $57 \%$ of our patients had been referred by their general practitioner suggests that such referral habits may influence GUM clinics' HSV morbidity statistics. For example over $20 \%$ of patients with first-episode genital herpes may be treated in the community by their general practitioner and some of those referred to GUM clinics, may be started on treatment. Do women who consult their general practitioner first with genitourinary symptoms do so because they prefer to be treated in the community or because they are unaware of GUM clinics? As most of our patients referred by general practitioners were young, it is possible that, owing to greater awareness of teenage sexual health generated by "The Health of the Nation" document, general practitioners are more likely to refer younger patients with genitourinary symptoms to the GUM clinic. Also, younger women in stable sexual relationships, without a history of STD, might not attribute genitourinary symptoms to STD and present to their general practitioner instead of GUM clinics.

In our clinic, HSV infection in women seems to be different from other STDs in that most patients are in stable sexual relationships and the prevalence of other concurrent STDs is very low. Unlike Ross et $a l^{1}$ who reported concomitant gonorrhoea in patients with HSV 2 but not HSV 1, none of the HSV infected women in our study harboured $N$ gonorrhoeae. Although a recent serological survey found a higher prevalence of HSV 2 among GUM clinic attenders than blood donors, ${ }^{10}$ and others have noted differences in prevalence of other concurrent STD $^{1}$ or past history of STD $^{8}$ between patients with HSV 1 and 2 ; in our study concurrent or past STD was comparable and very uncommon in women with either HSV 1 or 2 . Is symptomatic HSV infection then a disease for those with low risk of other STD in our catchment population? 


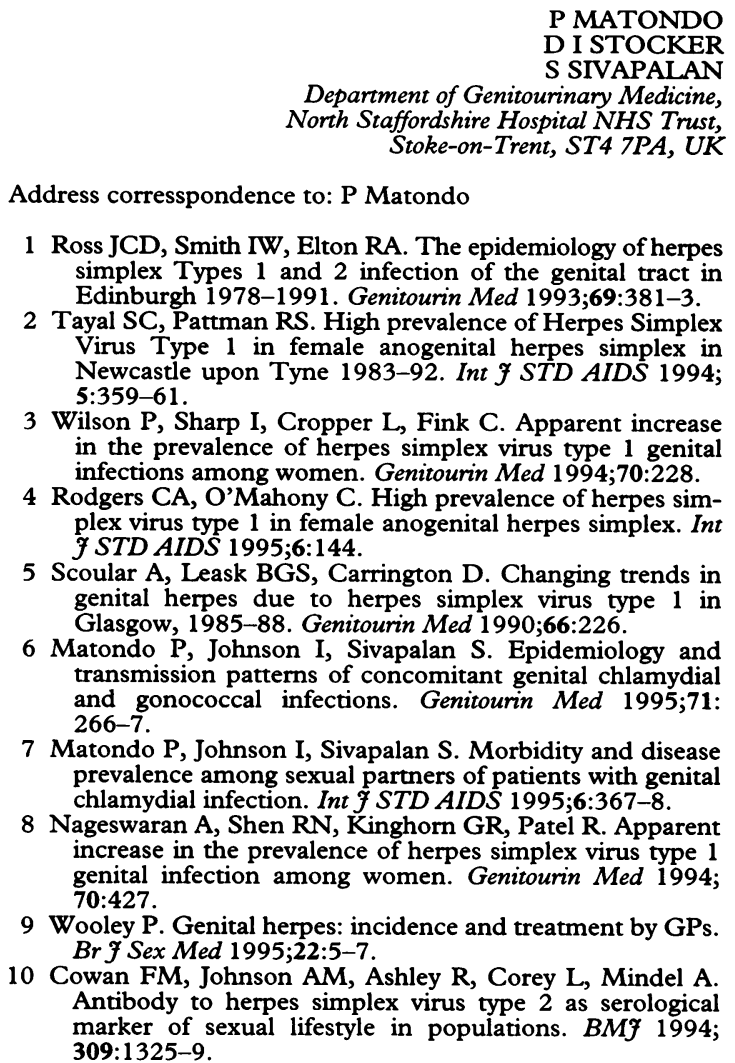

P MATONDO D I STOCKER S SIVAPALAN Department of Genitourinary Medicine, Department of Genitourinary Medicine,
North Staffordshire Hospital NHS Trust Stoke-on-Trent, ST4 7PA, UK

Address corresspondence to: P Matondo

1 Ross JCD, Smith IW, Elton RA. The epidemiology of herpes simplex Types 1 and 2 infection of the genital tract in
Edinburgh 1978-1991. Genitourin Med 1993;69:381-3.

2 Tayal SC, Pattman RS. High prevalence of Herpes Simplex Virus Type 1 in female anogenital herpes simplex in Newcastle upon Tyne 1983-92. Int $\mathcal{F} S T D$ AIDS 1994; 5:359-61.

3 Wilson P, Sharp I, Cropper L, Fink C. Apparent increase in the prevalence of herpes simplex virus type 1 genital infections among women. Genitourin Med 1994;70:228.

4 Rodgers CA, O'Mahony C. High prevalence of herpes simplex virus type 1 in female anogenital herpes simplex. Int f STD AIDS 1995;6:144.

5 Scoular A, Leask BGS, Carrington D. Changing trends in genital herpes due to herpes simplex virus type 1 in Glasgow, 1985-88. Genitourin Med 1990;66:226.

6 Matondo P, Johnson I, Sivapalan S. Epidemiology and transmission patterns of concomitant genital chlamydial transmission patterns of concomitant genital chlamydial and $\mathrm{g}$.

7 Matondo P, Johnson I, Sivapalan S. Morbidity and disease prevalence among sexual partners of patients with genita chlamydial infection. Int f STD AIDS 1995;6:367-8.

8 Nageswaran A, Shen RN, Kinghorn GR, Patel R. Apparent increase in the prevalence of herpes simplex virus type genital infection among women. Genitourin Med 1994 70:427.

9 Wooley P. Genital herpes: incidence and treatment by GPs. Br F Sex Med 1995;22:5-7.

10 Cowan FM, Johnson AM, Ashley R, Corey L, Mindel A. Antibody to herpes simplex virus type 2 as serological marker of sexual lifestyle in populations. BMf 1994; marker of sex

Accepted for publication 10 October 1995.

\section{Successful treatment of donovanosis with ciprofloxacin}

Antibiotic treatment of donovanosis has been empirical, and includes tetracycline, ${ }^{1}$ chloramphenicol ${ }^{2}$ and cotrimoxazole. ${ }^{3}$ More recently, workers in Australia have described successful use of daily injections of cefriazone. ${ }^{4}$ Treatment has sometimes depended on the responsiveness of the organism to the antibiotic available in the geographical area concerned. ${ }^{5}$ The causative organism, Calymmatobacterium granulomatis, a gram negative encapsulated bacterium is difficult to grow on artifical media thus limiting in vitro antibiotic sensitivity studies.

We have succesfully treated donovanosis with ciprofloxacin and report our first case. A 38 year old male from Zambia presented with a ten day history of two painless ulcers on the penis, and no other complaints. He had been in a relationship for one year with his girlfriend, who was in Zambia. Their last sexual intercourse was three weeks prior to presentation. He denied having any other sexual partner during this year.

General examination was unremarkable. His skin and oral mucosa showed no abnormality. He had swollen non tender right inguinal lymph nodes and two ulcers on the prepuce, each about a centimeter in diameter which were clearly demarcated, had thickened edges and minimal granulation tissue. Dark ground microscopy, serological tests for Treponema pallidum, culture for Haemophilus ducreyi, and herpes simplex virus cell cultures were performed. Five days later, the penile ulcers had increased in size, still with well defined edges (fig 1). Dark ground microscopy for $T$ pallidum was again negative. We sus-

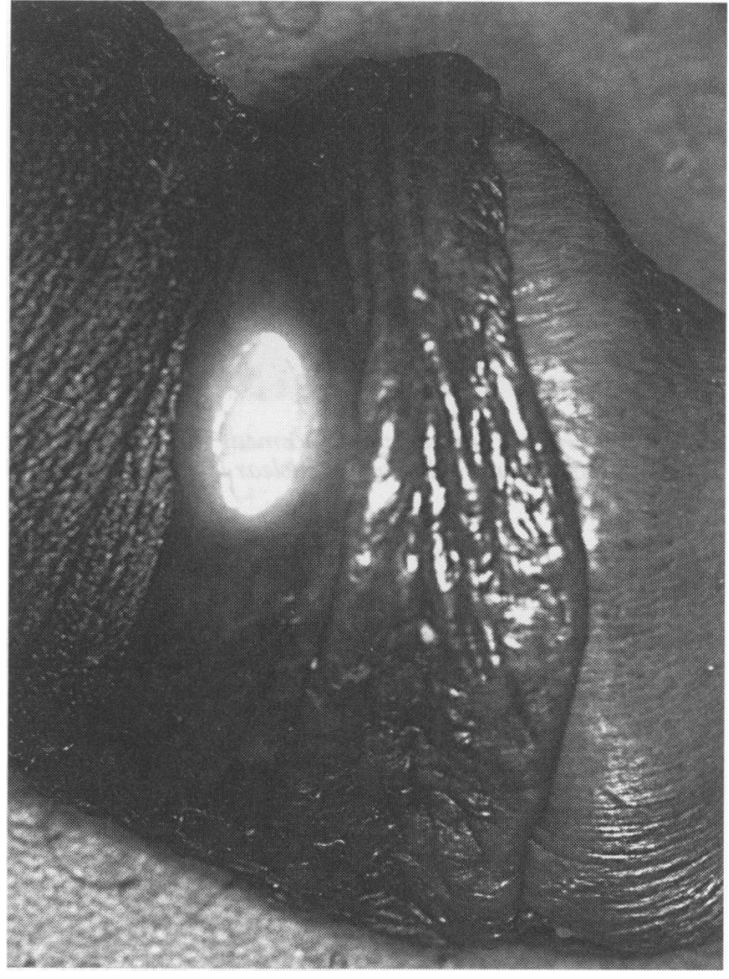

Figure 1 Penis showing one of the ulcers.

pected donovanosis and a biopsy of the edge of one of the ulcers was performed. The patient was started on a two week course of oxytetracycline $500 \mathrm{mg}$ qds orally, but on its completion there was no notable change in the size or appearance of the ulcers. The result of the initial investigations were all negative, but donovanosis was identified on a Giemsa stained specimen (fig 2) and confirmed on histology. In view of this failure to respond to oxytetracycline, we decided to try him on ciprofloxacin, since this has a wide spectrum of activity and is particularly active against gram negative organisms. Commencement on ciprofloxacin $500 \mathrm{mg}$ bd orally was followed by a marked response in the first 7 days, and complete re-epithelisation of the penile ulcers within 2 weeks.

Following this experience, we have successfully used ciprofloxacin as first line treatment in two other patients with genital ulcers cytologically and histologically confirmed as donovanosis. These patients also experienced complete re-epithelisation of their genital ulcers within 2 weeks of starting ciprofloxacin. None of the patients reported any adverse effect from the drug. We would recommend ciprofloxacin as drug of first choice in the treatment of early donovanosis, since it it very effective, inexpensive, and relatively free from adverse effects.

$$
\begin{array}{r}
\text { B A AHMED } \\
\text { A TANG } \\
\text { Department of Genitourinary Medicine, } \\
\text { Royal Berkshire Hospital, London Road, } \\
\text { Reading, Berkshire, RG1 } 5 \text { AN, UK }
\end{array}
$$

1 Zigas V. Medicine from the past; Donovanosis project in Gioilala (1951-1954). Papau New Guinea Medical fournal 1971;14:148.

2 Maddocks I, Anders E M, Dennis E. Donovanosis in Papua New Guinea. Genitourin Med 1976;52:190-6.

3 Latif A S, Mason P R, Paraiwa E. Treatment of donovanosis (granuloma inguinale). Sexually Transmitted Diseases 1988;15:27-9.

4 Merianos A, Gilles M, Chuah J. Ceftriaxone in the treatment of donovanosis in Central Australia. Genitourin Med 1994;70:84-9. 